\title{
TRABALHO DE CONCLUSÃO DE CURSO: TRABALHO INTERATIVO NA ORIENTAÇÃO EM EAD
}

\author{
Keite Silva de Melo ${ }^{1}$ \\ Gilda Helena Bernardino de Campo ${ }^{2}$
}

\begin{abstract}
Resumo: O trabalho de conclusão de curso (TCC) na educação a distância $(\mathrm{EaD})$ é resultado da parceria entre orientando e orientador. Essa interação configura-se na temática desse trabalho, chamando a atenção para o trabalho interativo do orientador. No momento da escrita, o orientando busca apoio e segurança em seu orientador, mas há poucas pesquisas se dedicando a essa relação. Buscamos na literatura, as principais características do trabalho interativos empregados na orientação de TCC. Analisamos 25 trabalhos, categorizamos as caraterísticas por sua incidência e elencamos as dificuldades que fragilizam a relação afetiva entre orientador-orientando. Nota-se que o orientador precisa entregar um pouco de si ao trabalho. O envolvimento com o aluno, bem como sua dedicação e responsabilidade podem facilitar o relacionamento, e conduzir o percurso de forma dialógica e democrática.
\end{abstract}

Palavras-chave: Orientação de TCC; Trabalho interativo; Educação a distância.

\section{INTERACTIVE WORK IN DISTANCE LEARNING ORIENTATION: FINAL COURSE ASSIGMENT}

\begin{abstract}
The final work in specialization course in distance learning (DL) is the result of the partnership between the academic advisor and the student. This interaction is discussed in this work, drawing attention to the interactive work of the advisor. At the time of writing, the student seeks support and security in his supervisor, but there is little research devoted to this relationship. We searched in the literature the main characteristics of the interactive work employed in the orientation of the final work. We analyzed 25 studies, categorized the characteristics by their incidence and listed the difficulties that weaken the affective relationship between advisor and student. It should be noted that the supervisor needs to give some soul in his work. Involvement with the student, as well as his dedication and responsibility can facilitate the relationship and conduct the course in a dialogical and democratic way.

Key words: Academic advisor; Interactive work. Distance learning
\end{abstract}

\footnotetext{
${ }^{1}$ Doutoranda em Educação pela PUC-Rio, professora do curso de Pedagogia do ISERJ/FAETEC e professora licenciada para estudos pela SME-Duque de Caxias.

${ }^{2}$ Coordenadora Central de Educação a Distância (CCEAD PUC-RIO) e professora do Departamento de Educação (PUC-Rio).
} 


\section{INTRODUÇÃO}

A modalidade da Educação a distância $(\mathrm{EaD})$ vem crescendo significativamente no ensino superior, nos últimos anos. Segundo dados do Censo do Ensino Superior de 2016 (INEP, 2017), o “número de matrículas na modalidade a distância continua crescendo, atingindo quase 1,5 milhão em 2016, o que já representa uma participação de $18,6 \%$ do total de matrículas da educação superior." (INEP, 2017, p. 7).

Gráfico 1 - Número de matrículas em cursos de graduação, por modalidade de ensino - Brasil 2006-2016

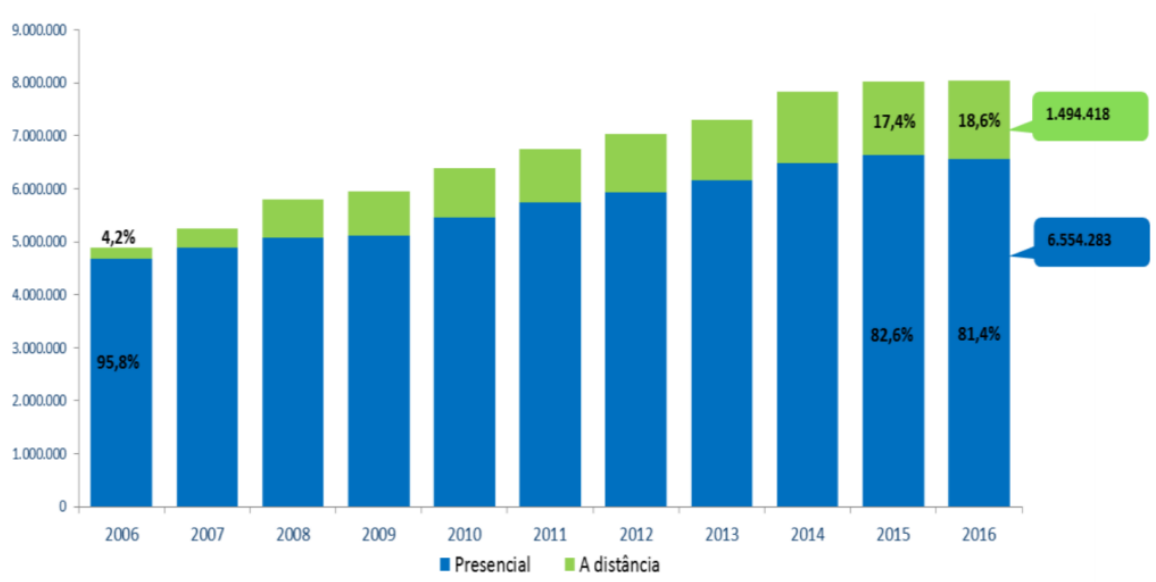

Fonte: Notas Estatísticas do Censo da Educação Superior 2016 (INEP, 2017).

Embora tenha havido aumento no ingresso de alunos na educação superior pela modalidade $\mathrm{EaD}$, houve uma pequena queda $(1,3 \%)$ no número de concluintes em relação ao ano anterior (INEP, 2017). Para avaliar melhor o fluxo, será necessário retomar esse volume mais expressivo no ingresso apresentado no relatório atual, com o número de concluintes daqui a 4 ou 5 anos. Somente assim será possível avaliar como a modalidade está impactando o fluxo de alunos. Apesar disso, é possível antever um avanço da modalidade na Educação Superior, que seria impulsionada pela autorização para oferta de cursos de pós-graduação Stricto Sensu na modalidade EaD ${ }^{3}$ (BRASIL, 2017). Com essa autorização, surgem também grandes desafios: formação para os professores desse segmento para atuarem na modalidade, infraestrutura física e técnica

\footnotetext{
${ }^{3}$ Segundo o artigo $3^{\circ}$ da Resolução $\mathrm{n}^{\circ} 7$ de 11 de dezembro de 2017, as instituições credenciadas poderão propor programas de mestrado e doutorado na modalidade $\mathrm{EaD}$, faltando para isso, regulamentação da CAPES para o os procedimentos de avaliação desses cursos.
} 
para viabilizar o projeto pedagógico e pesquisas voltadas à especificidade da pós Stricto sensu, convergindo com a mediação via Tecnologias Digitais da Informação e Comunicação (TDIC).

Atualmente o segmento que mais oferta cursos regulamentados é a pósgraduação lato sensu (MBA e especialização), campo de investigação desse nosso estudo. Segundo o CensoEaD de 2016 (ABED, 2017), no último ano houve uma oferta de 1.098 cursos, alcançando cerca de 49.400 alunos nesse nível de ensino. Os cursos de pós-graduação lato sensu possuem normas semelhantes à educação presencial para avaliação de fim de curso, como provas presenciais e defesa presencial do trabalho de conclusão de curso (TCC), conforme indicado no Parágrafo Único da Resolução $\mathrm{n}^{\mathrm{o}} 1$ do Conselho Nacional de Educação em 2007 (CES/CNE, 2007).

O TCC, embora seja uma construção autoral individual, não é resultado de um esforço de um sujeito apenas, mas da parceria entre orientando e seu orientador. Essa interação subsidia a temática desse trabalho, chamando a atenção para o trabalho investido do professor-orientador.

O trabalho investido (TARDIF; LESSARD, 2014) configura-se como o envolvimento da personalidade do profissional no seu ofício, característica própria das profissões que lidam com a interação com outros sujeitos, mas em especial, o magistério, que possui uma demanda afetiva intensa em todos os segmentos e modalidades. Na pós-graduação lato sensu, no momento da escrita autoral do TCC, principalmente quando o aluno ainda não adquiriu a autonomia acadêmica, a busca por apoio, segurança e acolhimento em seu orientador, torna-se a centralidade de suas ações, principalmente nos primeiros contatos com esse professor.

Paralela a essa necessidade do orientando, há a dimensão pessoal do professororientador, que marca e define a forma como vai conduzir a orientação do TCC e como construirá os laços e interação durante o percurso com o seu orientando. Como a produção científica que se dedica a investigar a relação entre orientador-orientando, retrata o trabalho investido do professor-orientador no processo de orientação? Quais as características, segundo as pesquisas mais recentes, do trabalho interativo na orientação de TCC? Essas são algumas questões que norteiam esse trabalho, que possui a primeira seção voltada para discussão da orientação de TCC na EaD, depois apresentamos o conceito de trabalho interativo e como o mesmo se insere na orientação de TCC, continuamos o conceito de trabalho interativo, mas com as abordagens do diálogo e autoria discente como subjacentes ao mesmo e realizamos uma pesquisa bibliográfica 
com 25 trabalhos voltados para orientação de TCC, com o objetivo de verificar como a literatura recente descreve as principais caraterísticas do orientador, voltadas à afetividade e o trabalho interativo.

\section{A ORIENTAÇÃO DE TCC DA MODALIDADE EAD}

A educação a distância (EaD) vem se apropriando do avanço das TDIC e da convergência das mídias, potencializando a interação entre os sujeitos, em espaços formais e informais de aprendizagem, podendo adotar em seu projeto pedagógico, a hibridização dos espaços e tempos por meio do b-learning (SANTAELLA, 2013) ou modalidade semipresencial. A EaD conta com um professor online (geralmente vinculado como professor-tutor), que realiza a mediação através das diversas interfaces síncronas e assíncronas do ambiente virtual de aprendizagem (AVA), com destaque para os fóruns de discussão, que vêm sendo a interface mais adotada em cursos formais online, nas áreas humanas.

Em cursos de pós-graduação lato sensu na modalidade EaD, eventualmente contrata-se outro profissional para realizar a orientação de TCC, ou quando é o mesmo profissional que realizou a mediação das disciplinas até o final do curso, é-lhe exigido outro perfil de mediação para essa etapa de conclusão do curso. A produção do TCC possui distintas demandas que se intensificam e complexificam a dedicação, autonomia e autoria discente no curso. Para isso, o professor que assume a orientação precisaria formar-se previamente para a especificidade da orientação, ou quando a formação prévia não estiver garantida, conforme relatam vários autores (MACHADO, 2006; MARINELLI; CARVALHO, 2010; SANTOS; MAFFEI, 2010; CONTI; SILVA, 2010), esse profissional precisaria desenvolver os saberes docentes in loco. Por tratar-se de uma fase do orientando de maior esforço, quando a autonomia lhe é mais exigida, a interação entre orientador-orientando ganha maior relevância e centralidade.

Chamamos a atenção nesse trabalho, para o envolvimento pessoal na orientação do TCC, lembrando de sua trajetória acadêmica com seus professores e orientadores anteriores, expectativas, frustrações, como vivenciou as relações de poder em sua trajetória e a forma como lida com a carga emocional da orientação. Entendemos que essas vivências imbricam-se com o ofício docente e identidade profissional, permeando 
as relações intersubjetivas que emergem da relação orientador-orientando, durante o percurso de construção desse trabalho científico.

A imersão pessoal no ato de orientar TCC ocorre mediada pelas tecnologias digitais adotadas pela $\mathrm{EaD}$ e se ancora no diálogo via escrita, na maior parte das vezes apoiando-se apenas na comunicação assíncrona. Tendo em vista que toda a comunicação entre orientador-orientando é viabilizada principalmente através da escrita, o orientador precisa considerar que "na escrita, como o tom de voz e o conhecimento do assunto são excluídos, somos obrigados a utilizar muito mais palavras, e com maior exatidão. A escrita é a forma de fala mais elaborada." (Vygotsky, 1998, p. 179).

Embora Vygotsky não estivesse tratando da escrita virtual, escrita essa baseada na interação propiciada pelos ambientes virtuais de aprendizagem, esse pressuposto vygotskyano está coerente para pensarmos a orientação do TCC a distância. Vemos grande importância em situar a comunicação via escrita para amparar a constituição de uma relação fecunda e emancipatória no processo de orientação, sem subestimar o trabalho interativo e a subjetividade dos sujeitos envolvidos nessa etapa de conclusão do curso.

\section{O TRABALHO INTERATIVO DO ORIENTADOR DE TCC}

O conceito de trabalho interativo (TARDIF; LESSARD, 2014) pode ser compreendido como um trabalho realizado com/para/sobre outros seres humanos, ação própria dos profissionais da relação ${ }^{4}$. As profissões que atuam com relações humanas, marcam a identidade desses trabalhadores, modificando o processo de trabalho, o profissional, as relações que envolvem o trabalho e a identidade profissional. Segundo os autores é possível distinguir as profissões como aquelas que atuam com trabalho material (manipuláveis fisicamente), as que atuam com trabalho cognitivo (trabalho intelectual com signos e materiais intangíveis) e as que atuam para/com/sobre o outro, o trabalho interativo. A docência, incluído aqui o orientador de TCC, estaria conciliando as duas categorias de trabalho: o interativo (com/sobre o outro) e o cognitivo (intelectual e mediador de signos).

\footnotetext{
${ }^{4}$ Alguns exemplos de profissões que lidam com relações humanas: psicólogos, médicos, policiais, carcereiros, assistentes sociais, advogados, consultores, vendedores, enfermeiros, etc.
} 
Tardif e Lessard (2014) chamam a atenção para a entrega da pessoa na profissão, de sua personalidade, constituindo assim, a sua identidade pessoal e profissional de forma imbricada.

Esse trabalho sobre o humano evoca atividades como instruir, supervisionar, servir, ajudar, entreter, divertir, curar, cuidar, controlar, etc. Essas atividades se desdobram segundo modalidades complexas em que intervêm a linguagem, a afetividade, a personalidade, ou seja, um meio em vista de fina: o terapeuta, o docente, o trabalhador de rua engaja diretamente sua personalidade no contato com as pessoas e estas os julgam e os acolhem em função dela. Componentes como o calor, a empatia, a compreensão, a abertura do espírito, etc., constituem, então, os trunfos inegáveis do trabalho interativo. (TARDIF; LESSARD, 2014, p. 33).

Retomando o papel do orientador enquanto profissional do trabalho interativo, entendemos que ele possui a sua marca e prática próprias e as investe nas relações significativas com os orientandos. Essa entrega da pessoa demanda tamanha energia e engajamento, que pode levar ao esgotamento. Essa é uma das características do trabalhador interativo, que se constitui enquanto trabalho emocional, emergindo cotidianamente no exercício profissional, como uma tecnologia essencial da profissão.

É importante ressaltar que o trabalho docente, diferente da maior parte das profissões de relações humanas, possui desafios cotidianos próprios, dentre eles:

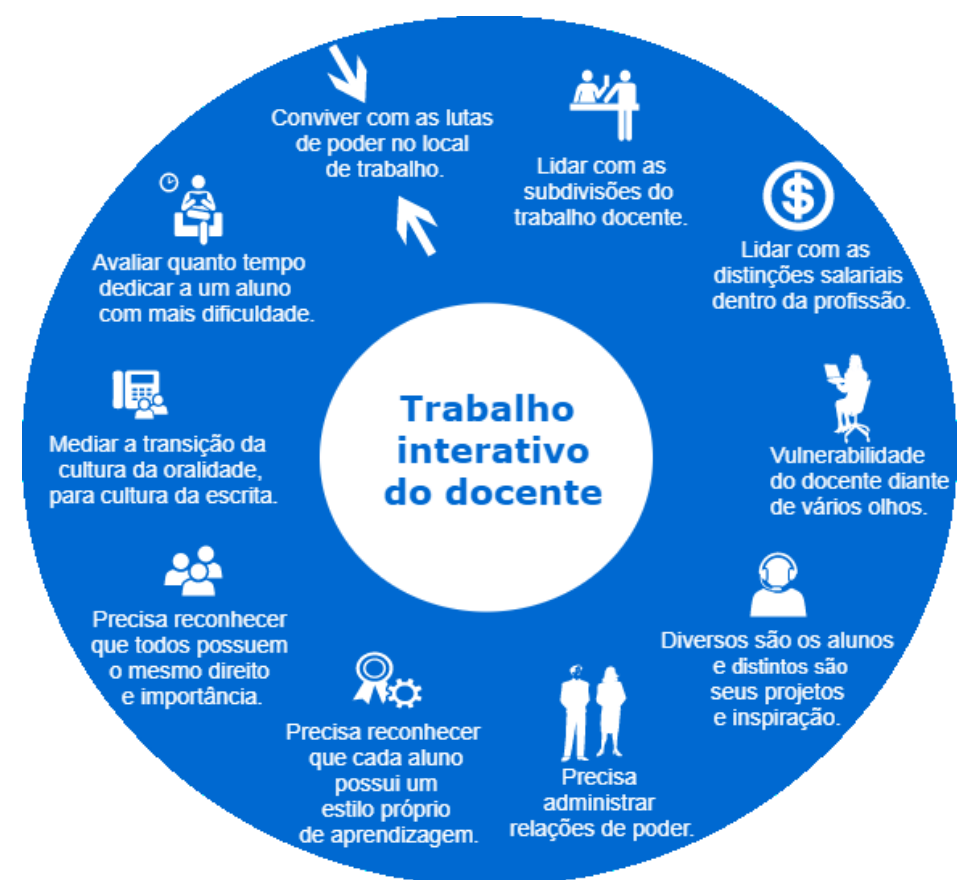

Figura 1. Alguns desafios do trabalho interativo docente, segundo Tardif e Lessard (2014).

Fonte: Autoria própria. 
Há ainda, uma invasão da vida particular do orientador, seja para preparar os feedbacks, para formar-se ou para avaliações e atividades extras (relatórios, por exemplo) que compõem a cultura educacional de cursos da pós-graduação via EaD. Essa carga de trabalho, geralmente no formato de home office ou teletrabalho ${ }^{5}$ (MILL e FIDALGO, 2009), invade a vida pessoal e doméstica, trazendo uma sobrecarga mental ao professor, e muitas são consideradas tarefas invisíveis (se atualizar quanto às mídias, contribuição com mais opções de literatura pertinente ao TCC, orientação quanto às normas da $\mathrm{ABNT}$, produzir tutoriais para formatação do texto segundo as normas da instituição, entre outros). As tarefas invisíveis são as que geralmente exigem maior envolvimento afetivo.

$\mathrm{O}$ trabalho interativo dos orientadores traz à tona questões complexas que incluem: "poder, da afetividade e da ética" (TARDIF; LESSARD, 2014, p. 30), podendo inclusive conter conflitos de valores, já que os orientandos são portadores de identidade própria. Geralmente profissionais em busca de aprofundar seus conhecimentos e, portanto, possuidores de conhecimento próprio sobre a área, além de situarem-se em universos culturais distintos entre si e distinto do orientador.

A particularidade do trabalho docente, enquanto trabalho interativo exige que haja uma ética bem internalizada, para que não ocorram abusos (de poder) devido à relação assimétrica. Outra particularidade é que o atendimento ao objetivo do seu trabalho, neste artigo, a conclusão do TCC, depende da participação dos orientandos, que são convocados a realizar essa tarefa para concluir o curso, a fim de obter a certificação desejada. Com isso, como pode parecer uma etapa desafiadora para muitos, nem sempre a adesão é voluntária ou proativa, podendo ser marcada por apatia, demandando dos orientadores um processo de convencimento para fazê-los aderir à atividade de orientação. Esse convencimento se constrói de forma distinta em cada relação, com cada orientando, e pode incluir a lembrança do motivo que os trouxeram até aquele curso, apoio para a escrita acadêmica, orientação para organização pessoal quanto a prazos, e estímulo constante para desenvolverem a necessária autonomia para essa produção.

\footnotetext{
${ }^{5}$ Trabalho a distância mediada por equipamentos digitais, eletrônicos ou de comunicação. Mill e Fidalgo (2009) lembram que o discurso da qualidade de vida incutido na cultura dos profissionais da $\mathrm{EaD}$, quando estes podem atuar em sua residência ou em qualquer espaço-tempo, traz subjacente a fragilidade de limite entre tempo de trabalho e tempo livre para a família ou outra demanda pessoal, podendo inclusive se converter em trabalho integral.
} 
Segundo Tardif e Lessard (2014), a interação significativa influência na constituição do trabalhador e do objeto do trabalho nessa relação professor-aluno, atravessada pela emoção e afetos próprios das relações humanas. A esse envolvimento da personalidade do trabalhador como instrumento do próprio trabalho, os autores chamam de "trabalho investido", ou seja, "um professor não pode, apenas, 'fazer o seu trabalho', mas que deve engajar-se e investir a si mesmo no que é como pessoa nesse trabalho.” (p. 268). A exigência do trabalho docente é, portanto, redobrada se comparada com outras profissões que empregam o trabalho interativo.

Canário (2006) e Nóvoa (2009) concordam que o trabalho docente inclui a totalidade da pessoa no exercício profissional. O campo de atuação docente em qualquer segmento e modalidade é marcado por afetos, sentimentos e por vezes, até mesmo conflitos. Sendo assim, os orientadores investem emoção no seu trabalho, por meio da relação interpessoal com os seus orientandos.

$\mathrm{Na}$ interação entre o orientador e o orientando durante a realização de um trabalho científico, "a importância do outro e da emotividade intrínseca às interações humanas em processos de aprender a orientar e ser orientado" (SCHNETZLER; OLIVEIRA, 2010, p. 50, grifos dos autores) se situam em um contexto sócio histórico de colaboração mútua. Essa interação ancora-se na subjetividade e em aspectos emocionais singulares, oriundos tanto dessa interação, quanto da especificidade da produção autoral do TCC, bem como a preparação para apresentação/defesa pública presencial.

Para Schnetzler e Oliveira (2010), a relação orientadora-orientando "é um espaço privilegiado em que os meandros da intersubjetividade podem apresentar impasses de natureza afetiva, que resultam em oportunidades de crescimento pessoal e intelectual dos envolvidos.” (p. 55). Sendo assim, a interação entre esses agentes se concretiza por meio do afeto mútuo (afetar e se deixar afetar), onde há ação, empatia, conflitos, entre outros sentimentos, mediados pela escrita do TCC, bem como das trocas constantes entres esses agentes, em contínua supervisão e incentivos para o orientando autorizar-se como autor.

\section{DIÁLOGO E AUTORIA DISCENTE COMO ELEMENTOS SUBJACENTES AO TRABALHO INTERATIVO}

Nessa singularidade do encontro de dois agentes comprometidos com dada produção, é possível surgir mal-entendidos, seja devido à pouca experiência de 
orientação na modalidade $\mathrm{EaD}$, seja algum ruído oriundo da falta de clareza e inteligibilidade, sendo que em todos os casos, o diálogo é fundamental. Estamos considerando o diálogo a partir do pressuposto por Vygotsky (1998), isto é, o diálogo possível, quando os interlocutores possuem conhecimento suficiente sobre o assunto em pauta. A comunicação que permeia esse diálogo precisa articular leveza, já que a tensão própria da produção de um trabalho acadêmico leva o orientando a contar com a experiência e segurança que um orientador pode propiciar. Esse professor, ao reconhecer os limites e potencialidades autorais do seu orientando, poderá avaliar a melhor forma de intervir, supervisionando e estimulando-o, para que a autonomia se constitua.

A consideração à peculiaridade do outro, no seu tempo, estado emocional, estilo de aprendizagem e capacidade autoral, através do diálogo que forma e reforma os sujeitos envolvidos e viabilizam a aprendizagem, pode contribuir para a superação das dificuldades e conflitos que porventura surjam. Os conflitos não devem ser silenciados, mas entendidos como próprios das diferenças históricas pessoais. Coelho (2011) sugere nesse caso, que se verifique inicialmente se "se esta divergência não é devido à ambiguidade presente na língua corrente ou ao emprego diferenciado das noções.” (p. 92).

O diálogo necessário buscará evitar o simples assentimento e até mesmo algum silenciamento de ideias e palavras, instaurado muitas das vezes, devido à relação de poder contido na díade: orientador-orientando. Estamos compreendendo o conceito de díade como preconizado por Campos et al, (2013) ao tratar da relação entre o mediador e o aluno em cursos na modalidade EaD. A díade

[...] estabelece uma situação de cooperação, como definida por Morton Deutsch (1973). Isso significa que há um único objetivo para esses participantes ligados de tal forma que o objetivo final só pode ser alcançado, e apenas se, ambos possam alcançar seus objetivos. (CAMPOS et al, 2013, p. 58-59).

As relações constitutivas entre mediador-aluno são similares às do orientadororientando, pois o objetivo de concluir o trabalho é compartilhado por essa díade. A autoridade existe e é necessária, pois o orientador, enquanto par mais capaz (VYGOSTKY 1998), se implica com o processo autoral do orientando, direcionando ou redirecionando o percurso através das trocas problematizadoras e parceria mútua. Durante a orientação, o orientador altera a sua função docente onde desempenha 
também o papel de corretor, para tornar-se leitor interessado da produção autoral discente. O conceito de autoria pode ser compreendido como

O compromisso com o conhecimento, com o sentido do que aprendemos. A proposta de passo a passo desvelar, compreender o que está escrito por muitos autores e atribuir um sentido pessoal ao que escrevemos sobre o que compreendemos daquilo que lemos, se configura como a autoria. Aqui vale lembrar as relações emergentes entre o pensar, o falar e o escrever. Daí a preocupação do professor em estimular a reflexão, oportunizando a expressão das ideias e sua transcrição textual. (NUNES, 2005, p. 307).

O trabalho interativo do orientador precisa instaurar o diálogo, onde a autoria discente é vista como a autorização da própria escrita e autoconhecimento: A escrita dos alunos nos parece indicar que o significado de autoria
construído por eles, em função do tempo vivido na pesquisa, diz
respeito à ideia de escrita de punho próprio, de se posicionar, de ter o
"direito" de escrever o que pensa. Certamente, que autoria passa por
esses constructos, mas não se esgota neles. O conhecimento de si, a
capacidade de se ver a partir dos seus escritos, o estar dobrado, voltado
para dentro, como condição de implicação, de autoformação e
interformação, se revelou como potência, como possibilidade de um vir
a ser na continuidade de práticas/vivências que valorizem aprendizagens
multirreferenciais e autorais dos praticantes situados na cibercultura."
(RIBEIRO; BARBOSA; SANTOS, 2014, p. 66-67).

A autoria não tem sido estimulada na maior parte das instituições da Educação Básica (DIAS, 2017), mas esse mesmo problema pode ser encontrado na graduação (KRAMER, 2000), quando a autoria se traduz em retórica (MACHADO, 2006), exposição oral, seminários, entre outras estratégias que priorizam a oralidade. Possuir uma graduação não está diretamente relacionada ao exercício de produção autoral, por meio da escrita. Kramer (2000) lembra como os alunos da graduação possuem dificuldade em se autorizarem por meio da escrita. Chegam, então, à pós-graduação com a mesma dificuldade, cristalizadas devido o passar do tempo. Nesse desafio da escrita supervisionada, o orientador implica-se com o TCC do seu orientando, apoiando-o "para conquistar a coragem necessária para assumir suas posições e argumentos, desenvolvê-los por escrito e entregá-los ao público" (idem, p. 62). A orientação nesse sentido compromete-se com a pessoa do orientando, com sua autoria, por meio do afeto, mas precisa conciliar essa afetividade com a necessária autonomia, evitando uma possível dependência se a relação for marcada por excessos e permissividades. 
Massi e Giordan (2017) lembram que ainda não há um campo de investigação que se aprofunde sobre a função da orientação, tratando-se de uma demanda urgente para a pesquisa e instituições de ensino superior:

[...] a maior parte das universidades e dos pesquisadores brasileiros ainda não percebeu quão complexa e fundamental é essa discussão sobre o papel, a atuação e a formação do orientador, sobretudo em um momento tão grave pelo qual passa todo o sistema público de educação do país, vitimado pelo congelamento de investimentos no setor por duas décadas. (p. 15).

Diante dessa ausência, e por acreditarmos que há um impacto no profissional e no exercício de sua função, oriunda do trabalho interativo próprio da orientação, nos dedicamos a investigar como a literatura mais recente vem retratando a abordagem do trabalho interativo na orientação de TCC. Priorizamos as pesquisas que se debruçaram sobre a modalidade $\mathrm{EaD}$, mas não nos limitamos a esta, uma vez que acreditamos que algumas das principais características do trabalho interativo empregadas na orientação, podem ser reconhecidas nas distintas modalidades e segmentos que empregam um trabalho final de curso, incluídas aí, monografias, teses, dissertações e outros formatos de TCC.

\section{CARACTERÍSTICAS DO TRABALHO INTERATIVO NA ORIENTAÇÃO DE TCC: UM OLHAR A PARTIR DA LITERATURA}

Em pesquisa no Google Acadêmico, com as palavras-chave: "orientação de TCC" e "orientação acadêmica" no período de 2007-2018, obtivemos 16.200 resultados. Em uma primeira triagem, optamos por analisar 30 trabalhos (desconsiderando nesse momento, teses, dissertações e TCC) com maior aderência à nossa intencionalidade. No segundo refinamento dos dados, descartamos os artigos que, embora tratassem da orientação de TCC, se dedicaram a uma dessas abordagens: verificavam quais as interfaces foram mais utilizadas por orientadores e orientandos, defendiam a manutenção do TCC em curso de formação de professores de dada área, descreviam a proposta pedagógica da instituição para o processo de orientação ou analisavam estatisticamente o acesso de orientadores no AVA. Restaram $25 \operatorname{artigos}^{6}$ para serem analisados, com o objetivo de retratar o trabalho interativo no processo de

\footnotetext{
${ }^{6} \mathrm{~A}$ relação completa dos trabalhos analisados pode ser acessada no link: https://drive.google.com/open?id=1RG8oC-qDpNjhqJq-1GB9aR6-z19knA9z.
} 
orientação. Apresentamos então, categorias que reúnem as características com maior ocorrência nos distintos trabalhos. $\mathrm{Na}$ categoria Administração foi necessário diferenciar as instituições públicas, das instituições vinculadas à UAB (também formada por instituições públicas), pois alguns cursos citados nos trabalhos não estavam vinculados a essa última, dentre eles, os cursos de Pós-graduação Stricto Sensu.

Os trabalhos que fazem parte desse escopo podem ser retratados em termos percentuais, da seguinte forma:

\begin{tabular}{|c|c|c|c|c|}
\hline \multirow[t]{2}{*}{ SEGMENTO } & $\begin{array}{l}\text { Retratam curso de } \\
\text { aperfeiçoamento }\end{array}$ & $\begin{array}{l}\text { Retratam a } \\
\text { graduação }\end{array}$ & $\begin{array}{l}\text { Retratam a pós } \\
\text { lato sensu }\end{array}$ & $\begin{array}{l}\text { Retratam a pós } \\
\text { stricto sensu }\end{array}$ \\
\hline & $4 \%$ & $40 \%$ & $32 \%$ & $24 \%$ \\
\hline \multirow[t]{2}{*}{ ADMINISTRA ÇÃo } & Pública & $\begin{array}{c}\text { Instituição } \\
\text { privada }\end{array}$ & UAB & Não delimita \\
\hline & $36 \%$ & $32 \%$ & $12 \%$ & $20 \%$ \\
\hline \multirow{2}{*}{$\begin{array}{l}\text { PERŔODO DA } \\
\text { PUBLICAÇ̧̃̃o }\end{array}$} & Entre 2007-2009 & Entre 2010-2012 & Entre 2013-2015 & $\begin{array}{c}\text { Entre } 2016 \text { a } \\
2017 \\
\end{array}$ \\
\hline & $12 \%$ & $60 \%$ & $12 \%$ & $16 \%$ \\
\hline \multirow{2}{*}{$\begin{array}{l}\text { MODALIDADE DA } \\
\text { ORIENTAÇÃO }\end{array}$} & EaD & Presencial & Semipresencial & Não delimita \\
\hline & $40 \%$ & $36 \%$ & $12 \%$ & $12 \%$ \\
\hline
\end{tabular}

Fonte: Elaboração própria.

A seguir, as principais características elencadas nos artigos analisados, que se relacionam com o trabalho interativo do orientador, durante a produção do TCC pelo orientando. Somente foram destacadas dos trabalhos, as características diretamente relacionadas com a abordagem do trabalho interativo ou com a constituição da afetividade durante a orientação do TCC.

A ordem das categorias apresentada a seguir está diretamente relacionada à incidência de cada característica nos trabalhos analisados. A primeira categoria foi apontada em 7 artigos, a segunda em 6, a terceira em 5, a quarta em 4, a quinta em 3, a sexta em 2 e na sétima foram reunidas características citadas uma única vez. Da terceira categoria à sétima, reunimos duas ou mais características, mantendo na categoria a mesma incidência com que foram citadas. Foi necessário fragmentar a sétima categoria, de forma a viabilizar o entendimento, pois a mesma ficou muito extensa.

Em nossa análise encontramos pelo menos oito trabalhos que associavam explicitamente a parceria entre orientador-orientando ou um bom relacionamento entre esses, com a qualidade do TCC. Sendo assim, após o levantamento e análise realizados, podemos reconhecer o orientador de TCC, que realiza a sua orientação baseada no trabalho interativo, como um profissional que: 
$1^{\circ}$ estabelece parceria;

$2^{\circ}$ possui agilidade no feedback;

$3^{\circ}$ usa linguagem acessível para quem está iniciando pesquisa e compreende os desafios pessoais e profissionais do orientando;

$4^{\mathrm{o}}$ assume o papel de guia, que demonstra confiança no desenvolvimento do orientando e aprende por meio da interação com esse;

$5^{\circ}$ possui experiência acadêmica na área que orienta e investe na relação interpessoal, acolhendo, apoiando e estimulando a autonomia;

$6^{\circ}$ não é autoritário e estimula a criação e produção autoral do orientando, reconhecendo o seu potencial, participando como principal interlocutor por meio da constituição de vínculo, sempre oferecendo: segurança, disponibilidade, cumplicidade, respeito mútuo e sintonia na relação;

$7^{\circ}$ pode ser associado como consultor, terapeuta, zeloso, aquele que investe na troca mútua, na união, buscando estabelecer uma via de mão dupla, baseada na reciprocidade. Precisa ser um profissional paciente, interlocutor e ouvinte sensível, disponível, que se envolve e é cuidadoso com a produção do aluno, facilitando a aprendizagem e providenciando orientações individuais e personalizadas, por meio de relação dialógica.

7.1 busca constituir um laço com o orientando, estabelecendo sintonia por meio do elogio às produções do orientando, evitando a inibição, ao mesmo tempo em que investe no afeto mútuo. Na caminhada onde estão juntos trocando, aposta, insere-se por meio da coparticipação, coautoria, em um ciclo de cooperação entre esses agentes;

7.2 respeita e considera os orientandos, bem como as diferenças, e em seu trabalho, assume o lugar de especialista, com olhar criterioso e boa formação quanto à habilidade de escrita. Também contribui com novos materiais, incentiva a interação no AVA, avalia os avanços durante o processo de orientação e providencia modelos e exemplos para tornar claro dado procedimento ou norma acadêmica, assim como adota outras mídias para estabelecer um elo mais positivo com orientando, com áudio e vídeo, de forma que o sorriso e tom voz de contribuam para um clima e ambiente agradáveis.

7.3 trabalha a produção de textos quando é constatada maior dificuldade nesse aspecto, buscando sempre a proximidade por meio da afetividade e por meio da aceitação das características mútuas, reconhecendo e tornando claro que ambos têm direitos e deveres e mais adiante, percebe o ganho do seu trabalho com o êxito profissional do seu exorientando. 
7.4 pode ser comparado como aquele que propicia um canal aberto, faz a mediação de angústias, estimula que o passo à frente seja dado, facilita o caminho, aponta o trajeto e ilumina o caminho.

As categorias anteriormente elencadas são fundamentais no processo de orientação baseado no trabalho interativo e na afetividade, mas como indicado nos dados coletados, a parceria é uma via de mão dupla, portanto, os orientandos possuem grande responsabilidade para que a interação se concretize e o trabalho seja viabilizado. Nos trabalhos analisados, foi possível localizar as seguintes categorias que interferem diretamente na viabilidade dessa interação, trazendo impacto de esgotamento não apenas no orientando, mas também no orientador:

- Alguns discentes não cumprem os requisitos mínimos de interação, outros criam certa dependência na relação com o orientador;

- $\quad$ O orientando precisa se envolver com o curso e com o seu trabalho, realizando as leituras pertinentes, ainda que os prazos estejam apertados e falte-lhe mais tempo para se dedicar. A organização e disciplina são fundamentais;

- $\quad$ Em alguns casos, orientadores possuem muitos orientandos, o que inviabiliza o atendimento mais cuidadoso subjacente às categorias anteriores;

- Como pode faltar amadurecimento quanto ao tema ou experiência quanto à escrita, as interferências do orientador podem ultrapassar a sua função/obrigação (copidesque, por exemplo), trazendo cansaço e frustração para esse profissional;

- Eventualmente há dificuldade de interpretação dos dados ou definição do objeto, levando o orientador a colocar-se de forma mais impositiva, o que não colabora com a conquista da autonomia.

Compreende-se dessa forma, que o impacto do trabalho interativo da orientação traz grande envolvimento da pessoa (orientador), exigindo-lhe funções distintas da docência ou tutoria e aproximando-o do pesquisador, mas sem se assemelhar totalmente a essa outra função. O comprometimento do trabalho interativo, baseado na afetividade (CASTRO; MELO; CAMPOS, 2018) e relações interpessoais vem sendo atravessado pela sobrecarga de trabalho docente, o que pode acometer esgotamento ao orientador e frustração e ansiedade ao orientando. Segundo Quixadá Viana e Veiga (2010),

Pagamos um alto preço pela submissão à lógica da reestruturação de políticas públicas, de modo específico na educação superior, no que se refere ao atendimento de desejos da acumulação capitalista, acolhendo o aligeiramento e a privatização do trabalho docente, consoante com sua desvalorização profissional. A educação, tratada como uma mercadoria, 
um bem de consumo, em estreita sintonia com a racionalidade produtiva, exige índices de produtividade. (p. 224-225).

Como Tardif e Lessard (2014) chamaram a atenção, o trabalho interativo do docente se difere de outras profissões com essa característica da relação humana, pois os docentes têm os seus próprios desafios. Atualmente no ensino superior brasileiro vemos uma crescente proletarização da docência, principalmente na modalidade EaD. Apesar disso, ainda que haja excesso de orientandos e precarização no vínculo trabalhista, a exigência do envolvimento da pessoa e da sua afetividade com os alunos, tem sido um desafio constantemente requerido.

\section{CONSIDERAÇÕES FINAIS}

Orientadores de TCC possuem uma missão complexa a ser instaurada por meio do diálogo cuidadoso: acionar a autonomia e autoria do orientando, pouco estimuladas anteriormente, orientando-o a aperfeiçoar sua escrita e expandi-la, usando para isso ações que vão desde a exigência até passando críticas construtivas e elogio. Quando adotada uma linguagem baseada na compreensão e cuidado, o rigor e exigência com a produção autoral, assim como com o cronograma, podem ser entendidos como cuidados próprios de quem se compromete e se implica com a afetividade, que fundamenta o trabalho interativo do orientador.

O acolhimento solicitado pelo orientando, durante o percurso autoral de sua produção do TCC, aciona no orientador a necessidade de dedicar-se, incluindo sua dimensão pessoal. As diversas categorias encontradas na literatura que desenham o pressuposto para um orientador, que entrega um pouco de si ao trabalho, são apenas um lado da via de mão dupla ou reciprocidade indicadas nos dados coletados. O envolvimento do aluno com o seu trabalho, sua dedicação e responsabilidade podem facilitar o bom relacionamento, e conduzir o percurso de forma dialógica e democrática.

Compreendemos com esse estudo, que muitos dos desafios da docência são somados aos desafios próprios da orientação, trazendo ao orientador de TCC da EaD, diversas outras demandas a serem conciliadas. Mesmo com prazos curtos, às vezes inflexíveis, e exigências complexas como o estímulo à autonomia e autoria em um tempo determinado pela instituição e não no tempo de cada sujeito, como se idealizaria, o diálogo e interação cuidadosos vêm sendo adotados, na maior parte das vezes. 


\section{REFERÊNCIAS}

BRASIL. Ministério da Educação. Conselho Nacional de Educação. Câmara de Educação Superior. Resolução $\mathrm{n}^{\circ} 7$ de 11 de dezembro de 2017. Diário Oficial da União. 12/12/2017, seção $1, \quad$ p. 21 . Disponível em: http://pesquisa.in.gov.br/imprensa/jsp/visualiza/index.jsp?data=12/12/2017\&jornal=515 \&pagina $=21 \&$ totalArquivos $=132$. Acesso em 10 jan. 2018.

BRASIL. Ministério da Educação. Conselho Nacional de Educação. Câmara de Educação Superior. Resolução $\mathbf{n}^{\circ}$ 1, de 8 de junho de 2007. Estabelece normas para o funcionamento de cursos de pós-graduação lato sensu, em nível de especialização. Brasília, DF, 2007. Disponível em: $<$ http://portal.mec.gov.br/cne/arquivos/pdf/rces001 07.pdf $>$. Acesso em: 5 abril de 2016.

CAMPOS, Gilda Helena Bernardino de; ZIVIANI, Cilio; SILVA, Eunice de Castro e ROQUE, Gianna Oliveira. Díade mediador-aluno: Relações de cooperação. Tecnologias, sociedade e conhecimento. vol. 1, n. 1, 2013. NIED, UNICAMP. Disponível em: http://www.nied.unicamp.br/ojs/index.php/tsc/article/view/110/98. Acesso em 24 mai. 2017.

CASTRO, Eunice; MELO, Keite Silva de; CAMPOS, Gilda Helena Bernardino de. Afetividade e motivação na docência online: um estudo de caso. RIED. Revista Iberoamericana de Educación a Distancia. v. 21, n. 1, 2018. Disponível em:

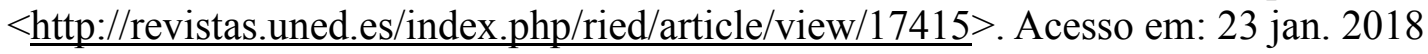

CANÁRIO, Rui. A escola tem futuro? Das promessas às incertezas. Porto alegre: Artmed, 2006.

Censo EAD.BR: relatório analítico da aprendizagem a distância no Brasil 2016 [livro eletrônico]/[organização] ABED - Associação Brasileira de Educação a Distância. Curitiba: InterSaberes, 2017. Disponível em: http://abed.org.br/censoead2016/Censo_EAD_2016 portugues.pdf. Acesso em 10 jan. 2018.

COELHO, M. B. Qualidade Argumentativa: Uma Competência Política na Esfera Pública. In: Ralph Ings Bannell; Rita Vilanova; Claudia Fenerich.. (Org.). A Formação para a Cidadania e os Limites do Liberalismo. Rio de Janeiro: 7 Letras., 2011, v. , p. 7-212.

CONTI, Clícia A. M. e SILVA, Jaci Lima da. Principais desafios da orientação: condições institucionais e relações interpessoais. In: SCHNETZLER, Roseli Pacheco e OLIVEIRA, Cleiton de. Orientadores em foco: o processo da orientação de teses e dissertações em educação. Brasília: Líber Livro Editora, 2010.

DIAS, Wagner Teixeira. Há espaço para construção autoral nos trabalhos de pesquisas escolares. Tese (doutorado). Pontifícia Universidade Católica do Rio de Janeiro, Departamento de Educação, 2017. 
Instituto Nacional de Estudos e Pesquisas Educacionais Anísio Teixeira. Notas estatísticas da Educação Superior 2016. Brasília: INEP, 2017. Disponível em: http://download.inep.gov.br/educacao superior/censo superior/documentos/2016/notas sobre_o_censo_da_educacao_superior_2016.pdf. Acesso em 10 jan. 2018.

KRAMER, Sônia. Escrita, experiência e formação - múltiplas possibilidades de criação de escrita. IN: ALVES-MAZZOTTI, Alda et al. Linguagem, espaços e tempos no ensinar e aprender. Rio de Janeiro: DP\&A, 2000.

MACHADO, Ana Maria Netto. A relação entre autoria e a orientação no processo de elaboração de teses e dissertações. In: BIANCHETTI, Lucídio; MACHADO, Ana Maria Netto. A bússola do escrever. Desafios e estratégias na orientação e escrita de teses e dissertações. $2^{\mathrm{a}}$ ed. São Paulo: Cortez editora, 2006.

MARINELLI, Célia Regina Gonçalves e CARVALHO, Raquel Alves. Histórias de Orientação: Ética, Responsabilidade e Compromisso com o Campo Científico. In: SCHNETZLER, Roseli Pacheco e OLIVEIRA, Cleiton de. Orientadores em foco: o processo da orientação de teses e dissertações em educação. Brasília: Líber Livro Editora, 2010.

MASSI, Luciana; GIORDAN, Marcelo. Formação do orientador de pesquisas acadêmicas: um estudo bibliográfico nacional e internacional. RBPG, Brasília, v. 14, 2017. Disponível em:

http://dx.doi.org/10.221713/2358-2332.2016.v14.1375. Acesso em 19 jan. 2018.

MILL, Daniel e FIDALGO, Fernando. O trabalho docente virtual como teletrabalho: sobre tempos, espaços e tecnologias. In: FIDALGO, Fernando; OLIVEIRA, Maria Auxiliadora M. e FIDALGO, Nara Luciene Rocha. (orgs). A intensificação do trabalho docente: Tecnologias e produtividade. Campinas, SP: Papirus, 2009.

NÓVOA, António. Os professores e o "novo" espaço público da educação. In: TARDIF, Maurice e LESSARD, Claude (orgs.). O ofício de professor. História, perspectivas e desafios internacionais. 3. Ed. Petrópolis, RJ: Vozes, 2009.

NUNES, Lina Cardoso. O processo de produção de hipertextos em curso superior: alternativa didática para constituir-se como autor. Educar. Curitiba, n. 25, p. 301-316, 2005. Disponível em: http://www.scielo.br/pdf/er/n25/n25a17.pdf. Acesso em 09 abr. 2017.

QUIXADÁ VIANA, Cleide Maria Quevedo; VEIGA, Ilma Passos Alencastro. O diálogo acadêmico entre orientadores e orientandos. Educação. Pontifícia Universidade Católica do Rio Grande do Sul. v. 33, n. 3, 2010.

RIBEIRO, Mayra Rodrigues Fernandes; BARBOSA, Joaquim Gonçalves; SANTOS, Edméa. Diário de pesquisa e aprendizagem multirreferencial na cibercultura. In: SANTOS, Edméa (org.) Diário online: dispositivo multirreferencial de pesquisaformação na cibercultura. Coleção Estudos Pedagógicos. Dinâmicas educacionais contemporâneas. Santo Tirso, Portugal: Whitebooks, 2014. 
SANTAELLA, Lucia. Comunicação ubíqua: repercussões na cultura e na educação. São Paulo: Paulus, 2013. Edição do Kindle.

SANTOS, Kátia Regina e MAFFEI, Willer Soares. Aprendendo a orientar. In: SCHNETZLER, Roseli Pacheco e OLIVERIA, Cleiton de. Orientadores em foco: o processo da orientação de teses e dissertações em educação. Brasília: Líber Livro Editora, 2010.

SCHNETZLER, Roseli Pacheco e OLIVEIRA, Cleiton de. Aspectos teóricometodológicos da investigação. In: SCHNETZLER, Roseli Pacheco e OLIVEIRA, Cleiton de. Orientadores em foco: o processo da orientação de teses e dissertações em educação. Brasília: Líber Livro Editora, 2010.

TARDIF, Maurice e LESSARD, Claude. O Trabalho docente - Elementos para uma teoria da docência como profissão de interações humanas. $9^{a}$ edição. Petrópolis: Vozes, 2014.

VYGOTSKY, L. S. Pensamento e Linguagem. 2a ed. São Paulo: Martins Fontes, 1998. 